\title{
Recursive Parallel Nonlinear Systems Identification
}

\author{
Adil $\mathrm{B}^{1 *}$, Mohamed $\mathrm{B}^{2}$ and Laila $\mathrm{K}^{3}$ \\ ${ }^{1}$ Department of AEEE Department, Moulay Ismail University, Morocco \\ ${ }^{2}$ Department of GE, Moulay Ismail University, Morocco \\ ${ }^{3}$ ENSAM, Moulay Ismail University, Morocco
}

Submission: February 05, 2018; Published: April 12, 2018

*Corresponding author: Adil B, ENSAM, AEEE Department, Moulay Ismail University, IMSM, L2MC, Meknes, Morocco, Email: a.brouri@ensam-umi.ac.ma

\begin{abstract}
Parallel nonlinear systems identification is studied. The system nonlinearity block can be noninvertible. The identification method can be
\end{abstract} dealt using hierarchical recursive least square algorithm.

Keywords : Nonlinear systems; Parallel nonlinear systems; Hierarchical method; Recursive/Iteration algorithm; Least square method

\section{Introduction}

The class of nonlinear systems studied in this paper is assumed to be modelled by parallel linear-nonlinear blocks. Such model is described by parallel connection of a memory less nonlinearity and a linear dynamic blocks (Figure 1). Black-box nonlinear system identification is a very wide research area [1]. The system identification is an essential step before the control of system [2]. The considerable diversity of nonlinear systems has led to a large variety of identification problems and a proliferation of identification approaches and methods [3-5]. In the area of parameter estimation, the hierarchical identification principle based on the decomposition technique can deal with parameter estimation for multivariable systems [6].

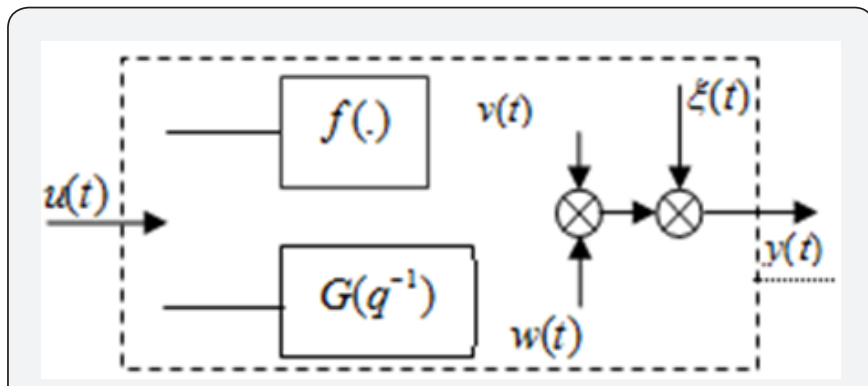

Figure 1: Parallel Nonlinear Systems.

In this paper, the problem of identifying parallel linearnonlinear block is addressed. Unlike many previous works, the nonlinearity element is of arbitrary-shape and can be noninvertible. The linear subsystem is of unknown parameters and order. Furthermore, the system nonlinearity is modeled by a linear basis function model. Some works are devoted to cancel the nonlinearity effects [7].

In most previous works devoted to parallel linear-nonlinear block system identification, the nonlinear element is supposed to be continuous. Presently, the identification algorithm is allowed to interest a wide range of the system nonlinearity. The identification problem amounts to determining an accurate estimate of the (nonparametric) nonlinearity, and the linear subsystem parameters . In this work, an identification recursive approach is dealt using hierarchical least square method to provide the system parameters estimate.

The paper is organized as follows: the nonlinear system to be identified is described in Section 2; The identification problem is formulated in Section 3; the system nonlinearity and the linear subsystem identification is coped with in Section 4; This paper will be concluded by a conclusion in Section5.

\section{Nonlinear System Description}

Standard parallel nonlinear systems consist of a memory less nonlinear element $f($.$) followed in series by a linear$ dynamic subsystem $G\left(q^{-1}\right)$ (Figure 1 ). This model is analytically described by the following equations:

$$
\begin{aligned}
& v(t)=f(u(t)) \\
& w(t)=g(t) * u(t) \text { or } \frac{w(t)}{u(t)}=G\left(q^{-1}\right)
\end{aligned}
$$




$$
\begin{gathered}
x(t)=v(t)+w(t) \\
y(t)=x(t)+\xi(t)=g(t) * u(t)+f(u(t))+\xi(t)
\end{gathered}
$$

where $g(t)$ is the impulse response of $G\left(q^{-1}\right)$; the symbol * refers to the convolution operation; $v(t)$ and $w(t)$ are the output signals of the nonlinearity block and the linear subsystem block respectively is the internal signal; $x(t)$ is the undisturbed output.

The only measurable signals are the system input $u(t)$ and system output $y(t)$. The equation error $\xi(t)$ is a zeromean stationary sequence of independent random variables; it accounts for external noise, it is supposed to be ergodic.

Because the system identification is carried out in open loop (Figure 1), the linear block $G\left(q^{-1}\right)$ must satisfy the stability asymptotically. Except for this assumption, the linear subsystem is arbitrary.

The system nonlinearity $f($.$) is supposed to be a nonlinear$ function of a known basis:

$$
F(u(t))=\left[f_{1}(u(t)), \ldots, f_{n}(u(t))\right]
$$

With unknown coefficients:

$$
\lambda=\left[\lambda_{1}, \ldots, \lambda_{n}\right]^{T}
$$

This later (i.e. $f($.$) ) is allowed to be noninvertible. Further,$ the considered linear subsystem is a rational function:

$$
G\left(q^{-1}\right)=\frac{B\left(q^{-1}\right)}{A\left(q^{-1}\right)}
$$

\section{The Problem Formulation}

Consider the polynomial functions $A\left(q^{-1}\right)$ and $B\left(q^{-1}\right)$ defined as follow:

$$
\begin{aligned}
& A\left(q^{-1}\right)=1+\sum_{k=1}^{n_{a}} a_{k} q^{-k}=1+a_{1} q^{-1}+\ldots+a_{n_{a}} q^{-n_{a}} \\
& B\left(q^{-1}\right)=\sum_{k=1}^{n_{b}} b_{k} q^{-k}=b_{1} q^{-1}+\ldots+b_{n_{b}} q^{-n_{b}}
\end{aligned}
$$

Then, it follows from (1b) and (3) that:

$$
w(t)=\left[1-A\left(q^{-1}\right)\right] w(t)+B\left(q^{-1}\right) u(t)
$$

Accordingly, the internal signal can be expressed as:

$$
w(t)=\theta^{T} \varphi(t)
$$

where:

$$
\begin{aligned}
& \theta=\left[a_{1}, \cdots, a_{n_{a}}, b_{1}, \cdots, b_{n_{b}}\right]^{T} \quad(7 a) \\
& \varphi(t)=\left[-w(t-1), \cdots,-w\left(t-n_{a}\right), u(t-1), \cdots, u\left(t-n_{b}\right)\right]^{T}
\end{aligned}
$$

Finally, one immediately gets from (1a-d), (6) and (7a-b) that:

$$
y(t)=F(u(t)) \lambda+\theta^{T} \varphi(t)+\xi(t) .
$$

We aim at designing an identification scheme that is able to provide a model estimate of system nonlinearity as well as an estimate $\hat{G}\left(q^{-1}\right)$ of linear block.

From (8) and combining the hierarchical identification principle with the least squares method, we can obtain the estimate of the nonlinear system parameters. The identification algorithm is described in the following section.

\section{Algorithm Identification}

The objective in this section is to present the steps of the nonlinear system identification. Then, from (8) and using the hierarchical identification method, the nonlinear system parameters estimate can be given using the least square algorithm. The computation process of this algorithm is summarized as:

\section{Step 1: Initialization}

Choose the basis function $f_{k}($.$) , e.g. polynomial basis$ function $f_{k}(u)=u^{k}$.

Let $\alpha=10^{6}$ and Set the initial values of the following matrices:

$$
\begin{gathered}
y(t)=1 / \alpha, \quad u(t)=1 / \alpha, \quad F(u(t))=1_{1 \times n} / \alpha \text { a } \quad \mathrm{n} \mathrm{d} \\
\varphi(t)=1_{\left(n_{a}+n_{b}\right) \times 1} / \alpha \text { for } t<0 \quad \text { (9a) } \\
P_{1}(0)=\alpha I_{n_{a}+n_{b}} \text { (9b) } \\
P_{2}(0)=\alpha I_{n} \text { (9c) }
\end{gathered}
$$

where $I_{k}$ is an $K \times K$ matrix identity.

Set the initial parameters vectors:

$\theta(0)=1_{\left(n_{a}+n_{b}\right) \times 1} / \alpha$ and $\lambda(0)=1_{n \times 1} / \alpha$

Let $t=1$.

Step 2: Data acquisition

Collect the input-output data $u(t)$ and $y(t)$.

Establish the matrices: $\varphi(t)$ using (7b) and $F(u(t))$ using (2a).

\section{Step 3:}

Compute the gain vector:

$$
L_{1}(t)=\frac{P_{1}(t-1) \varphi(t)}{I+\varphi^{T}(t) P_{1}(t-1) \varphi(t)}
$$

and the matrix:

$$
P_{1}(t)=\left[I-L_{1}(t) \varphi^{T}(t)\right] P_{1}(t-1)
$$

Update the parameters vector as follows: 


$$
\begin{aligned}
& \theta(t)=\theta(t-1) \\
& +L_{1}(t)\left[y(t)-F(u(t)) \lambda(t-1)-\theta^{T}(t-1) \varphi(t)\right]^{T}
\end{aligned}
$$

\section{Step 4:}

Compute the gain vector:

$$
L_{2}(t)=\frac{P_{2}(t-1) F^{T}(u(t))}{I+F(u(t)) P_{2}(t-1) F^{T}(u(t))}
$$

and the matrix:

$$
P_{2}(t)=\left[I-L_{2}(t) F(u(t))\right] P_{2}(t-1)
$$

Update the parameters vector $\theta(t)$ as follows:

$$
\begin{aligned}
& \lambda(t)=\lambda(t-1) \\
& +L_{2}(t)\left[y(t)-F(u(t)) \lambda(t-1)-\theta^{T}(t-1) \varphi(t)\right]
\end{aligned}
$$

Step 5: Increase $t(t=t+1)$ and go to step 2 .

\section{Conclusion}

The problem of system identification is addressed for parallel nonlinear systems. The system nonlinearity can be noninvertible. The identification of linear block and the nonlinearity element can be achieved simultaneously using a single stage (algorithm). Presently, the proposed identification scheme can be dealt using hierarchical recursive least square approach

This work is licensed under Creative Commons Attribution 4.0 License

DOI: 10.19080/RAEJ 2018.02555595
To the author's knowledge, unlike many of previous study, the present method has solved the identification problem for a large class of nonlinear systems structured by blocks. Furthermore, the proposed approach involves easily generated excitation signals and few input/output data acquisition.

\section{References}

1. Sijberg J, Zhang Q Ljung L, Benveniste A, Delyon B, et al. (1995) Nonlinear Black-box Modeling in System Identification: a Unified Overview, Automatica 31(12): 1691-1724.

2. Ljung L (1987) System Identification-Theory for the User. PrenticeHall, Englewood Cliffs, New Jersy, USA.

3. Brouri A, Amdouri O, Chaoui FZ, Giri F (2014) Frequency identification of Hammerstein-Wiener systems with piecewise affine input nonlinearity. $19^{\text {th }}$ IFAC World Congress, South Africa. pp. 10030- 10035

4. Brouri A, Giri F, Ikhouane F, Chaoui FZ, Amdouri O (2014) Identification of Hammerstein-Wiener systems with Backlash input nonlinearity bordered by straight lines. $19^{\text {th }}$ IFAC World Congress, South Africa 47(3): 475- 480

5. Brouri A, Slassi S (2016) Identification of Nonlinear Systems Structured by Wiener-Hammerstein Model. International Journal of Electrical and Computer Engineering 6(1): 167-176

6. Wang XH, Ding F (2015) Recursive parameter and state estimation for an input nonlinear state system using the hierarchical identification principle. Signal Process 117: 208-218.

7. Brouri A, Kadi L (2017) Frequency identification of HammersteinWiener systems with backlash input nonlinearity. Inter Jour of Cont Aut and Sys 15(5): 2222-2232.

\section{Your next submission with Juniper Publishers} will reach you the below assets

- Quality Editorial service

- Swift Peer Review

- Reprints availability

- E-prints Service

- Manuscript Podcast for convenient understanding

- Global attainment for your research

- Manuscript accessibility in different formats ( Pdf, E-pub, Full Text, Audio)

- Unceasing customer service

Track the below URL for one-step submission https://juniperpublishers.com/online-submission.php 